\title{
Conversion of the Major Birch Pollen Allergen, Bet v 1, into Two Nonanaphylactic T Cell Epitope-containing Fragments

\author{
Candidates for a Novel Form of Specific Immunotherapy
}

\author{
Susanne Vrtala, ${ }^{\star}$ Kora Hirtenlehner, ${ }^{\star}$ Luca Vangelista, ${ }^{\ddagger}$ Annalisa Pastore, ${ }^{\ddagger}$ Hans-Georg Eichler, ${ }^{\S}$ Wolfgang R. Sperr,, \\ Peter Valent, $\|$ Christof Ebner, ${ }^{*}$ Dietrich Kraft, ${ }^{*}$ and Rudolf Valenta* \\ *Department of Immunopathology, Institute of General and Experimental Pathology, AKH, University of Vienna, Austria; ${ }^{\ddagger}$ European \\ Molecular Biology Laboratory (EMBL), Heidelberg, Germany; ${ }^{\S}$ Department of Clinical Pharmacology, AKH, University of Vienna, \\ Austria; and ${ }^{\|}$Department of Internal Medicine I, Division of Hematology, AKH, University of Vienna, Austria
}

\begin{abstract}
A novel approach to reduce the anaphylactic activity of allergens is suggested. The strategy makes use of the presence of conformational immunoglobulin $\mathrm{E}$ (IgE) epitopes on one of the most common allergens. The three dimensional structure of the major birch pollen allergen, Bet $\mathrm{v} 1$, was disrupted by expressing two parts of the Bet $\mathrm{v} 1 \mathrm{cDNA}$ representing amino acids 1-74 and 75-160 in Escherichia coli. In contrast to the complete recombinant Bet $v 1$, the fragments showed almost no allergenicity and exhibited random coil conformation as analyzed by circular dichroism. Both nonanaphylactic fragments induced proliferation of human Bet $\mathrm{v}$ 1-specific $\mathrm{T}$ cell clones, indicating that they harbored all dominant $\mathrm{T}$ cell epitopes and therefore may be considered as a basis for the development of a safe and specific $\mathrm{T}$ cell immunotherapy. (J. Clin. Invest. 1997. 99:1673-1681.) Key words: major birch pollen allergen - Bet v 1 - recombinant allergen fragments $\bullet$ histamine release $\bullet$ skin testing
\end{abstract}

\section{Introduction}

Type I allergy represents a major health problem in industrialized countries where $>20 \%$ of the population suffers from type I allergic reactions (allergic rhinitis, conjunctivitis, allergic asthma, and anaphylactic shock) (1). Environmental proteins from pollen, mites, and animal dander belong to the major components which induce release of biological mediators (e.g., histamine) by cross-linking of effector cell (mast cell, basophil)-bound specific IgE antibodies. The production of specific $\mathrm{IgE}$ from $\mathrm{B}$ cells is stimulated by allergen-specific $\mathrm{T}$ helper cells which in their majority belong to the TH2 type (2). Therapy of type I allergic diseases is currently performed by pharmacological treatment and by specific immunotherapy. Specific immunotherapy was established early in this century (3)

Address correspondence to Dr. Rudolf Valenta, Institute of General and Experimental Pathology, AKH, University of Vienna, Währinger Gürtel 18-20, A-1090 Vienna, Austria. Phone: 43-1-40400-5108; FAX: 43-1-40400-5130.

Received for publication 14 August 1996 and accepted in revised form 21 January 1997.

J. Clin. Invest.

(C) The American Society for Clinical Investigation, Inc.

0021-9738/97/04/1673/09 \$2.00

Volume 99, Number 7, April 1997, 1673-1681 and involves the systemic application of increasing doses of allergens for extended periods. Although specific immunotherapy is recognized as effective treatment, the occurrence of anaphylactic side effects represents one of the major disadvantages of this therapy. To reduce anaphylactic reactions, the use of $\mathrm{T}$ cell epitopes has recently been proposed for allergen-specific immunotherapy $(4,5)$.

Allergens harbor a great variety of different $\mathrm{T}$ cell epitopes (6-8) which may overlap with continuous $\operatorname{IgE}$ epitopes. To prevent cross-linking of effector cell (mast cell, basophil)bound $\operatorname{IgE}$ and mediator release, $\mathrm{T}$ cell epitopes and $\operatorname{IgE}$ epitopes need to be dissected. Following the concept of converting a major allergen into a $\mathrm{T}$ cell vaccine, we have selected Bet v 1 (9), the major birch pollen allergen, as a model.

Bet v 1 was selected because epitope analysis indicated that it forms conformational IgE epitopes $(10,11)$. In addition, Bet $\mathrm{v} 1$ represents one of the most common allergens which is recognized by $95 \%$ of tree pollen and food allergic individuals and almost $60 \%$ of them are sensitized exclusively against Bet $\mathrm{v} 1$ (12). The cDNA coding for Bet $\mathrm{v} 1$ has been isolated recently (9) and recombinant Bet v 1 was expressed in Escherichia coli $(13,14)$. Recombinant Bet $\mathrm{v} 1$ has been shown to possess an IgE-binding capacity similar to that of natural Bet $\mathrm{v} 1$ and shares IgE as well as T cell epitopes with Bet v 1 homologous proteins present in pollen from various trees and in plantderived food $(6,15,16)$. The biological activity of recombinant Bet $\mathrm{v} 1$ has been demonstrated by histamine release experiments and by skin prick testing of allergic patients (17-19).

In this study we tested whether disruption of the Bet $v 1$ conformation may abolish allergenicity and simultaneously maintain relevant $\mathrm{T}$ cell determinants. The expression of two nonanaphylactic Bet $\mathrm{v} 1$ fragments which harbor all relevant known $\mathrm{T}$ cell epitopes of the complete Bet $\mathrm{v} 1$ molecule in $E$. coli, their purification, and structural and immunologic as well as their in vivo characterization as possible candidates for $\mathrm{T}$ cell-based specific immunotherapy are reported.

\section{Methods}

Sera from allergic patients, antibodies, protein extracts, plasmids, and E. coli strains. Sera from birch pollen allergic patients and control individuals were characterized by RAST and testing with recombinant allergens as described $(13,20)$. In addition, all patients were characterized by case history and skin prick test. The mouse mAb 14 with specificity for aa 40-66 of Bet $\mathrm{v} 1$ is described (21). Natural birch pollen extract was prepared as described (22). Plasmid pET-17b containing the ampicillin resistance and a $\mathrm{T} 7$ promoter was obtained from Novagen, Inc. (Madison, WI). Recombinant Bet v 1 fragments were expressed in $\lambda \mathrm{DE} 3$ lysogens of $E$. coli strain BL21 $\left(\mathrm{F}^{-}\right.$ompT $\left.\mathrm{r}_{\mathrm{B}}-\mathrm{m}_{\mathrm{B}}-\right)(23)$. 
Expression of Bet $v 1$ (aa 1-74, aa 75-160) fragments in E. coli. Recombinant Bet v 1 fragments (aa 1-74 and aa 75-160) were generated to maintain the epitopes (aa 44-60) of murine monoclonal antibodies which inhibited binding of allergic patients IgE to Bet v 1 (21) and to preserve major $\mathrm{T}$ cell epitopes which had been mapped using overlapping peptides synthesized according to the Bet $\mathrm{v} 1$ sequence (6). The cDNAs coding for fragment aa 1-74 and 75-160 were obtained by PCR amplification of the Bet $\mathrm{v} 1 \mathrm{cDNA}$ using the following oligonucleotide primers (Pharmacia, Uppsala, Sweden): Bet v 1 (aa 1-74): 5' GGG AAT TCC ATA TGG GTG TTT TCA ATT AC 3'; 5' CGG GGT ACC TTA CTC ATC AAC TCT GTC CTT 3'; Bet v 1 (aa 75-160): 5' GGG AAT TCC ATA TGG TGG ACC ACA CAA

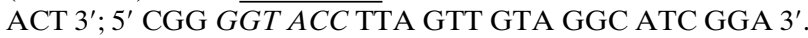

The EcoRI sites which were incorporated in the first primers are underlined, NdeI and KpnI sites are printed in italics. To improve subcloning efficiency, PCR products were first cut with EcoRI and KpnI, purified by preparative agarose gel electrophoresis, subcloned into EcoRI and KpnI sites of plasmid pET-17b (Novagen, Inc.), and transformed into E. coli BL 21 (DE3) (Novagen, Inc.) by electroporation. Inserts were then excised with $\mathrm{NdeI} / \mathrm{KpnI}$ and subcloned again in plasmid pET-17b and transformed. Colonies expressing the correct fragments were identified by immunoscreening using $\mathrm{mAb} 14$ for Bet v 1 aa $1-74$ and a rabbit anti-Bet v $1 \mathrm{COOH}$-terminal antiserum for Bet $\mathrm{v} 1$ aa $75-160$. DNA from positive clones was isolated using Qiagen tips (Qiagen, Hilden, Germany) and both DNA strands were sequenced according to Sanger using a T7 polymerase sequencing kit (Pharmacia) and $\left[{ }^{35} \mathrm{~S}\right] \mathrm{dCTP}$ (NEN, Stevenage, United Kingdom) (24). Recombinant Bet v 1 (aa 1-74) and Bet v 1 (aa 75-160) were expressed in E. coli BL 21 (DE 3) by induction with $0.5 \mathrm{mM}$ isopropyl$\beta$-thiogalactopyranoside at an OD600 of $0.5-0.8$ in liquid culture for $5 \mathrm{~h}$ at $37^{\circ} \mathrm{C}$.

Purification of recombinant Bet $v 1$ (aa 1-74) and Bet $v 1$ (aa 75 160). Recombinant Bet v 1 (aa 1-74) and recombinant Bet v 1 (aa 75-160) were expressed in inclusion bodies isolated as described (25). Inclusion bodies were solubilized with $8 \mathrm{M}$ urea, $10 \mathrm{mM}$ Tris, $\mathrm{pH} 8$, $1 \mathrm{mM}$ EDTA, $5 \mathrm{mM}$-mercaptoethanol, diluted with $10 \mathrm{mM}$ Tris, $\mathrm{pH} 8$, to a concentration of $6 \mathrm{M}$ urea and centrifuged for $15 \mathrm{~min}$ at $10,000 \mathrm{~g}$ to remove insoluble material. The supernatant, containing the recombinant protein, was dialyzed to a final concentration of $2 \mathrm{M}$ urea. After centrifugation ( $15 \mathrm{~min}, 10,000 \mathrm{~g}$ ), the supernatant was applied to a DEAE Sepharose (Pharmacia) column, and the protein was eluted with a $0-0.5 \mathrm{M} \mathrm{NaCl}$ concentration gradient. Fractions, containing the recombinant protein which was $>80 \%$ pure, were dialyzed against $6 \mathrm{M}$ urea, $10 \mathrm{mM} \mathrm{NaH}_{2} \mathrm{PO}_{4}, \mathrm{pH} 4.8$, and rechromatographed on an SP Sepharose column (Pharmacia). Fractions, containing recombinant Bet $\mathrm{v} 1$ (aa 1-74) or recombinant Bet $\mathrm{v} 1$ (aa 75-160) of $>95 \%$ purity, were dialyzed against $10 \mathrm{mM}$ Tris, $\mathrm{pH} 7.5$, and lyophilized until use.

Circular dichroism analysis of purified Bet $v 1$ fragments. Circular dichroism $(\mathrm{CD})^{1}$ spectra were recorded on a spectropolarimeter (model J-710; Jasco, Inc., Easton, MD) fitted with a thermostated cell holder and interfaced with a water bath (model RTE-110; NESLAB Instruments, Inc., Portsmouth, NH). The instrument was calibrated with a $0.10 \%$ aqueous solution of D-10-camphor-sulfonic acid. The results were expressed as the mean residue ellipticity at a given wavelength. Far ultraviolet $\mathrm{CD}$ spectra were recorded at $20^{\circ} \mathrm{C}$ in a $1-\mathrm{mm}$ path-length quartz cuvette (Hellma, Jamaica, NY), at protein concentrations ranging from 4 to $53 \mu \mathrm{M}$, depending on the experiment and the protein under analysis. Spectra were recorded with $0.1 \mathrm{~nm}$ resolution and results were expressed as an average of 10 scans. Final spectra were corrected by subtracting the corresponding base line spectra, obtained for the buffer under identical conditions. All measurements were performed in $20 \mathrm{mM}$ potassium phosphate, $\mathrm{pH}$ 7.0, containing $20 \mathrm{mM} \mathrm{NaCl}$.

1. Abbreviation used in this paper: $\mathrm{CD}$, circular dichroism.
IgE-binding capacity of recombinant Bet $v 1$ and Bet $v 1$ fragments. Purified recombinant Bet v 1 and Bet $\mathrm{v} 1$ fragments (aa 1-74, aa 75-160) were tested for IgE-binding capacity by Western blotting and in dot blot assays. For immunoblotting, $\sim 1 \mu \mathrm{g} / \mathrm{cm}$ purified protein was separated by SDS-PAGE (26) and blotted onto nitrocellulose according to Towbin (27). To avoid denaturation of the proteins, dot blot experiments were performed in parallel. $1 \mu \mathrm{g}$ purified recombinant Bet $\mathrm{v} 1,1 \mu \mathrm{g}$ of each Bet $\mathrm{v} 1$ fragment, and $1 \mu \mathrm{g}$ of BSA and HSA (negative controls) were dotted on nitrocellulose strips.

Nitrocellulose strips containing Western blotted allergens or the dot blotted proteins were incubated with serum IgE from allergic individuals, nonallergic control individuals, and buffer without addition of serum as described (28). Bound $\operatorname{IgE}$ antibodies were detected with ${ }^{125}$ I-labeled anti-human IgE antibodies and visualized by autoradiography using Kodak XOMAT films and intensifying screens (Kodak, Heidelberg, Germany) at $-70^{\circ} \mathrm{C}$.

Bet $v$ 1-specific $T$ cell clones, $T$ cell proliferation assays. T cell lines were established by incubating PBMC of birch pollen allergic volunteers with Bet $\mathrm{v} 1(10 \mu \mathrm{g} / \mathrm{ml})(6)$. T cell blasts from Bet $\mathrm{v} 1$-specific $\mathrm{T}$ cell lines were seeded in limiting dilution ( 0.3 cells/well) in 96-well round-bottom plates (Nunclone; Nunc, Roskilde, Denmark) together with $10^{5}$ irradiated (5,000 rad) allogeneic PBMC as feeder cells, 1\% vol/vol PHA (Gibco Laboratories, Grand Island, NY), and rIL-2 (Boehringer Mannheim, Mannheim, Germany) (4 U/well). The specificity of the $\mathrm{T}$ cell clones was determined by incubating $2-5 \times 10^{4} \mathrm{~T}$ cell blasts in triplicate cultures in 96-well plates together with $10^{5}$ autologous irradiated PBMC with birch extract, purified nBet $\mathrm{v} 1$, rBet $\mathrm{v} 1$, and overlapping peptides spanning the Bet $\mathrm{v} 1$ sequence for $48 \mathrm{~h}$ at $37^{\circ} \mathrm{C}, 5 \% \mathrm{CO}_{2}$ in a humidified atmosphere. Cells were then pulsed for $16 \mathrm{~h}$ with $\left[{ }^{3} \mathrm{H}\right]$ thymidine and harvested, and $\left[{ }^{3} \mathrm{H}\right]$ uptake was determined by scintillation counting. Proliferative responses were considered positive when the stimulation index (ratio between cpm obtained in cultures with $\mathrm{T}$ cell clones plus autologous irradiated PBMC plus antigen and cpm obtained in cultures containing $\mathrm{T}$ cell clones and PBMC alone) exceeded 10. Nine Bet $\mathrm{v} 1$-specific $\mathrm{T}$ cell clones, recognizing eight relevant $\mathrm{T}$ cell epitopes (6), were selected for experiments with Bet $\mathrm{v} 1$ fragments.

Histamine release experiments. Granulocytes were isolated from heparinized blood of birch pollen allergic individuals by dextran sedimentation (29). Cells were incubated with different concentrations $(0.001-10 \mu \mathrm{g} / \mathrm{ml})$ of purified recombinant Bet $\mathrm{v} 1$, recombinant Bet $\mathrm{v}$ 1 fragments (aa 1-74, aa 75-160) separately and in an equimolar mixture, or anti-human IgE antibodies. Histamine released in the supernatant was measured by RIA (Immunotech, Marseille, France) (17). Total histamine was determined in cell lysates after freeze thawing. Results were obtained as mean values from triplicate determinations and expressed as a percentage of total histamine release.

Skin testing. Skin prick tests were performed on the individuals' forearms by placing $20 \mu \mathrm{l}$ of each solution $(18,19)$. Recombinant Bet $\mathrm{v} 1$ and recombinant Bet $\mathrm{v} 1$ fragments were freshly dissolved in a $0.9 \% \mathrm{wt} / \mathrm{vol}$ sterile sodium chloride solution at concentrations of 100 and $10 \mu \mathrm{g} / \mathrm{ml}$. As controls, birch pollen SQ (standard quality) extract, sodium chloride solution (negative control), and histamine hydrochloride (positive control) (ALK, Horsholm, Denmark) were used. Each drop was pricked with a fresh prick lancet (ALK) and results were recorded after 20 min with a ball point pen by transferring the wheal area with a tape to paper and by photography. The mean wheal diameter (Dm) was calculated by measuring the maximal longitudinal diameter (D) and the maximal transversal diameter (d) according to the formula: $[D+d] / 2=D m$.

\section{Results}

Purification of recombinant Bet $v 1$ fragments to homogeneity. Recombinant Bet $\mathrm{v} 1$ fragments were expressed using plasmid pET-17b (Novagen, Inc.) and E. coli BL21 (DE3) in liquid culture. The Coomassie blue-stained SDS-PAGE in Fig. $1 A$ 

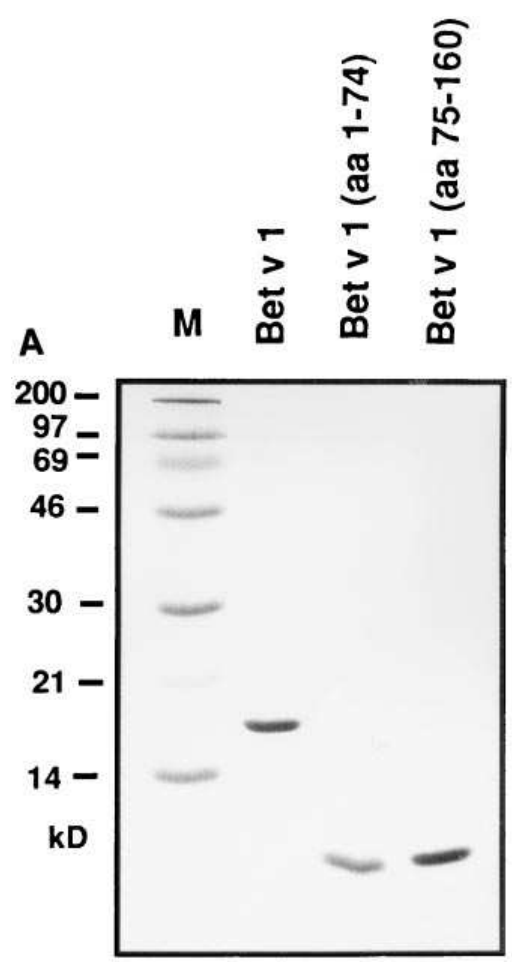
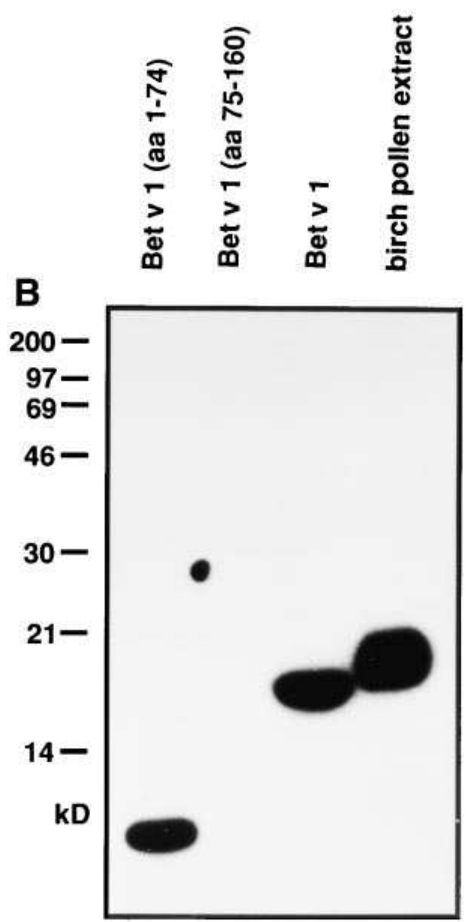

Figure 1. Purification of recombinant Bet $\mathrm{v} 1$ fragments. In $A, 2 \mu \mathrm{g}$ each of purified recombinant Bet $\mathrm{v} 1$ and the two Bet v 1 fragments (aa 1-74, aa 75-160) were analyzed by SDS-PAGE and Coomassie blue staining. In lane $M$, a molecular weight marker was loaded. $B$ shows the reactivity of nitrocellulose blotted natural birch pollen extract, recombinant Bet $\mathrm{v} 1$, and the two Bet $\mathrm{v} 1$ fragments with a mouse monoclonal antibody recognizing aa 44-66 of Bet $v 1$. The bound monoclonal antibody was detected with a ${ }^{125}$ I-labeled sheep anti-mouse antiserum and visualized by autoradiography. shows that pure recombinant Bet $\mathrm{v} 1$ fragments (aa 1-74, aa $75-160)$ were obtained by the purification protocol. The purified fragments were $>95 \%$ soluble as evaluated by subjecting the dissolved proteins to high speed centrifugation and subsequent analysis of the supernatant and pellet fraction (data not shown).

The immunoblot in Fig. $1 \mathrm{~B}$ shows that the binding site for a mouse monoclonal antibody located between aa 44-66 on the complete Bet v 1 molecule was preserved on the Bet v 1 fragment aa 1-74. The mouse monoclonal antibody was able to discriminate Bet v 1 fragment aa 1-74 and aa 75-160 indicating the presence of different B cell epitopes on the fragments.

$C D$ analysis of recombinant Bet $v 1$ fragments (aa 1-74, aa 75-160). Far ultraviolet CD spectra of the purified recombinant Bet v 1 fragments aa 1-74 and aa 75-160 (Fig. 2 A) indi- cate that the proteins contain predominantly random coil conformation. No variations in the CD spectra were observed upon mixing the two fragments at equimolar concentration (Fig. 2 B). Several spectra were recorded over a time range of $18 \mathrm{~h}$ from the equimolar solution preparation and no changes were observed in the dichroic signal (data not shown). From this it may be concluded that the two recombinant fragments do not show any tendency to fold, even in the presence of each other. In addition, no sign of aggregation was observed after analysis of different sample concentrations: Bet $\mathrm{v} 1$ fragment aa 1-74 (13 and $53 \mu \mathrm{M})$, fragment aa 75-160 (5 and $23 \mu \mathrm{M})$, and two equimolar solutions ( 4 and $15 \mu \mathrm{M}$ ) (data not shown).

IgE-binding of allergic patients to recombinant Bet $v 1$ fragments is almost completely abolished. We compared the IgEbinding capacity of recombinant Bet $\mathrm{v} 1$ and the two Bet $\mathrm{v} 1$
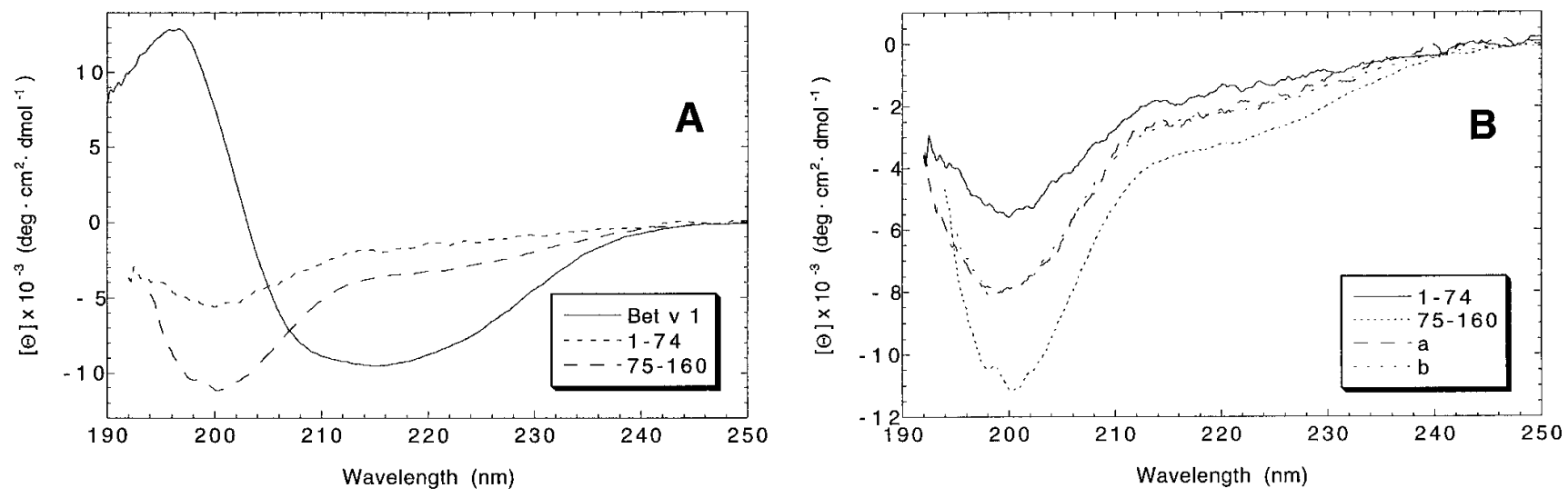

Figure 2. Far ultraviolet CD spectra of recombinant Bet v 1 and recombinant Bet v 1 fragments (aa 1-74, aa 75-160). (A) Complete recombinant Bet v $110 \mu \mathrm{M}$; fragment 1-74 $14 \mu \mathrm{M}$; fragment 75-160 $23 \mu \mathrm{M}$. (B) Fragments as in $A$; $(a)$ fragments 1-74 and 75-160 in equimolar solution $(4 \mu \mathrm{M}) ;(b)$ fragments $1-74$ and $75-160$ in equimolar solution $(15 \mu \mathrm{M})$. Spectra are expressed as mean residue ellipticity $([\Theta])$ at $20^{\circ} \mathrm{C}$. Proteins were in $20 \mathrm{mM}$ potassium phosphate, $\mathrm{pH} 7.0$, containing $20 \mathrm{mM} \mathrm{NaCl}$. 


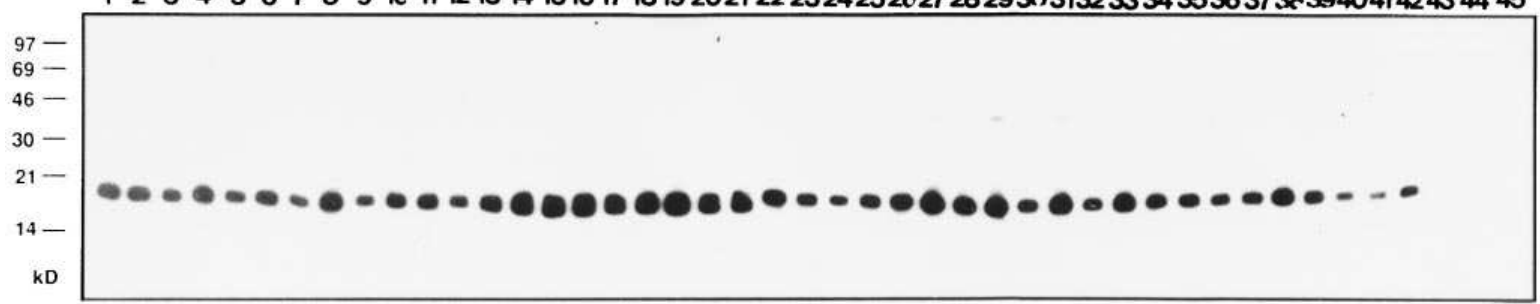

Bet $v 1$

$12345678910 \pi 12131415161718192021222324252627282930313233343536373839404142434445$

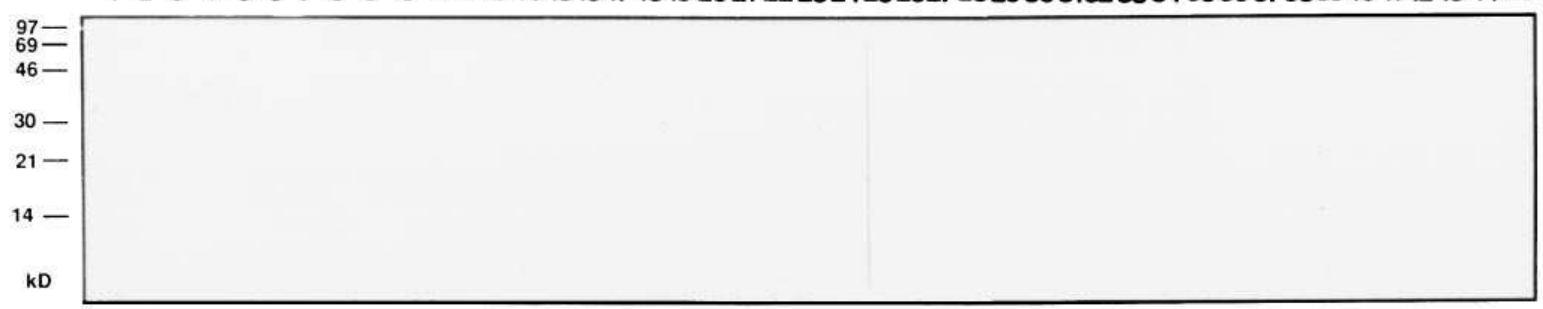

Bet $v 1$

(aa 1-74)

$12345678910 \pi 12131415161718192021222324252627282930313233343536373839404142434445$

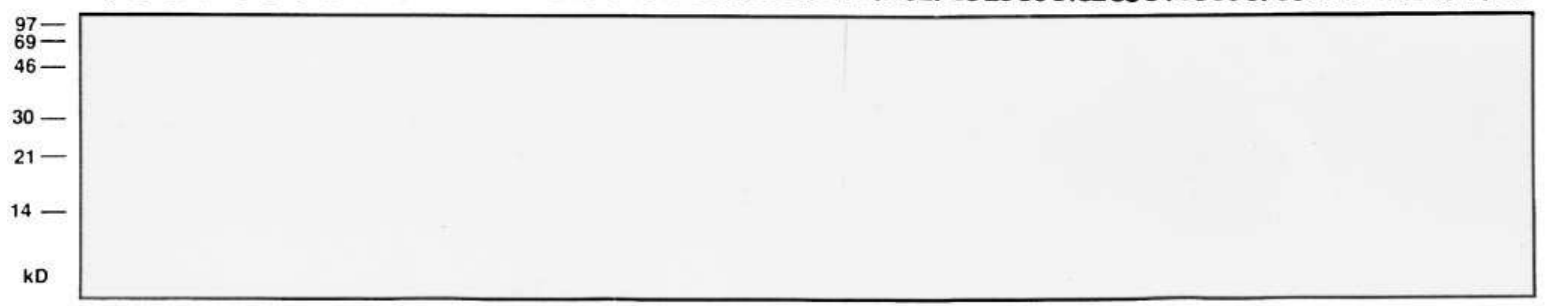

Bet v 1

(aa 75-160)

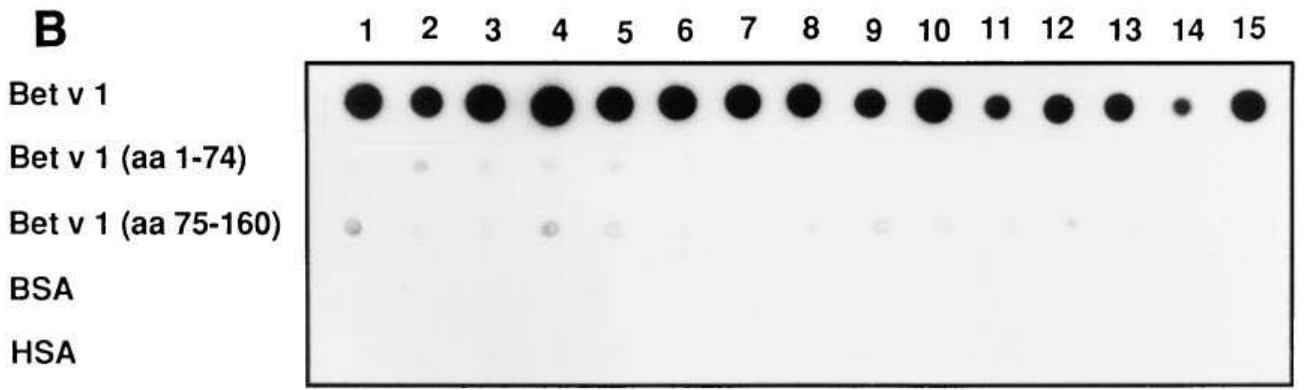

Figure 3. IgE-binding capacity of recombinant Bet $\mathrm{v} 1$ and recombinant Bet $\mathrm{v} 1$ fragments. $A$ shows the IgE reactivity of sera from 42 birch pollen allergic individuals (lanes 1-42), a grass pollen allergic patient without birch pollen allergy (lane 43), a nonallergic individual (lane 44), and buffer without addition of serum with the nitrocellulose blotted proteins. In $B$, sera from additional 15 birch pollen allergic individuals were tested for IgE reactivity with dot-blotted purified Bet v 1, purified Bet v 1 fragments (aa 1-74, aa 75-160), BSA, and HSA. Bound IgE was detected with ${ }^{125}$ I-labeled anti-human IgE antibodies (Pharmacia) and visualized by autoradiography.

fragments (aa 1-74, aa 75-160) using Western blotting as well as nondenaturing dot blot assays. Sera from 42 birch pollen allergic patients displayed IgE reactivity to nitrocellulose blotted recombinant Bet $\mathrm{v}$ 1, whereas no IgE-binding to any of the two recombinant Bet $\mathrm{v} 1$ fragments (aa 1-74, aa 75-160) could be detected (Fig. $3 \mathrm{~A}$ ). Sera from a grass pollen allergic individual and a nonallergic person as well as buffer controls showed no IgE reactivity to Bet $\mathrm{v} 1$ or the recombinant fragments (Fig. $3 \mathrm{~A}$, lanes 43-45).

Fig. $3 B$ shows the IgE reactivity of sera from 15 additional birch pollen allergic patients with dot blotted recombinant Bet $\mathrm{v} 1$, the recombinant Bet $\mathrm{v} 1$ fragments (aa 1-74, aa 75-160), and control proteins (BSA, HSA). All sera displayed intensive
IgE reactivity to the complete recombinant Bet $\mathrm{v} 1$ (aa 1-160) whereas almost no IgE binding to the Bet $\mathrm{v} 1$ fragments could be detected. The weak binding observed for sera 1-5, 8, 9, and 12 was estimated to represent $<1 / 1,000$ of the reactivity to the complete Bet v 1 allergen by densitometry. No serum showed IgE binding to the control proteins (BSA, HSA).

Recombinant Bet $v 1$ fragments a 1-74 and 75-160 harbor the relevant $T$ cell epitopes of complete Bet $v 1$. The $T$ cell epitopes of nine Bet v 1-specific $\mathrm{T}$ cell clones established from four different birch pollen allergic patients were determined by mapping with synthetic overlapping dodecapeptides. The ability of the two recombinant Bet $v 1$ fragments aa 1-74 and aa 75-160 to induce specific proliferation was investigated using $\mathrm{T}$ cell 


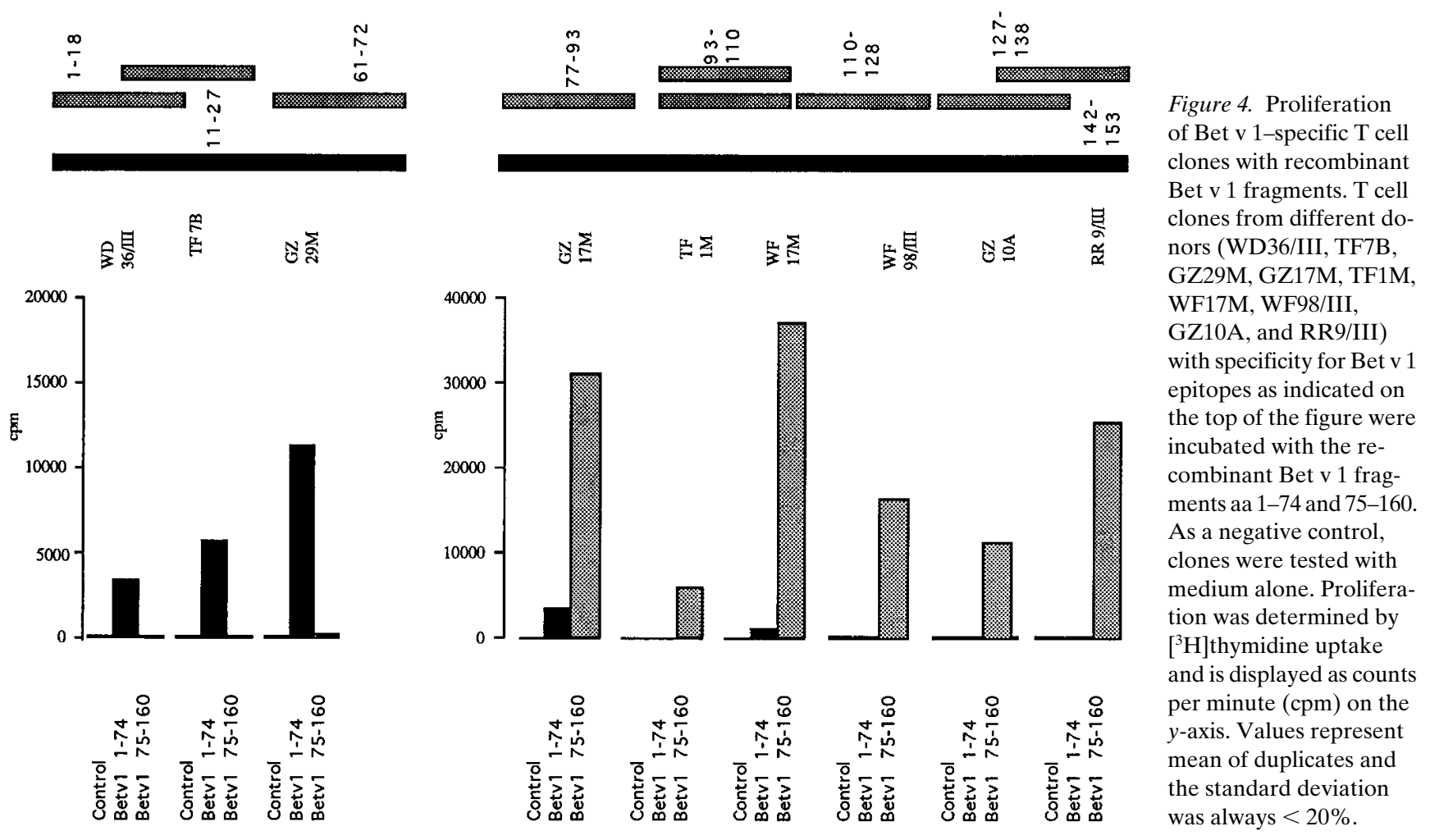

clones. $\mathrm{T}$ cell clones with specificity for $\mathrm{T}$ cell epitopes on the protein's $\mathrm{NH}_{2}$-terminal portion showed proliferation after incubation with fragment aa 1-74 while those clones which were mapped to the $\mathrm{COOH}$-terminal part proliferated in response to fragment aa 75-160. Using both recombinant Bet v 1 fragments or the complete Bet v 1 molecule (data not shown), significant proliferation could be induced in all nine $\mathrm{T}$ cell clones indicating that the combination of both fragments harbors all $\mathrm{T}$ cell epitopes of the complete Bet $\mathrm{v} 1$ molecule. No significant proliferation was observed when the $\mathrm{T}$ cell clones were

tested with medium and feeder cells without addition of antigen (Fig. 4, medium control).

Recombinant Bet $v 1$ fragments have $\sim 1,000$-fold reduced capacity to induce histamine release from patients' basophils. Fig. 5 shows representative results obtained from the comparison of complete recombinant Bet $v 1$ and the two Bet $v 1$ fragments in basophil histamine release experiments in two donors. Granulocytes from two different Bet v 1 allergic patients (Fig. 5, top and bottom) were incubated with different concentrations $(0.001-10 \mu \mathrm{g} / \mathrm{ml})$ of complete recombinant Bet v 1 (aa

Table I. Recombinant Bet v 1 Fragments (aa 1-74; aa 75-160) Are Nonanaphylactic in Allergic Patients' Skin

\begin{tabular}{|c|c|c|c|c|c|c|c|c|c|c|}
\hline \multirow[b]{2}{*}{ Individual } & \multirow[b]{2}{*}{ Histamine } & \multirow[b]{2}{*}{ Birch } & \multicolumn{2}{|c|}{ Bet v 1} & \multicolumn{2}{|c|}{ aa $1-74$} & \multicolumn{2}{|c|}{ aa $75-160$} & \multicolumn{2}{|c|}{ aa $1-74+$ aa $75-160$} \\
\hline & & & $10 \mu \mathrm{g} / \mathrm{ml}$ & $100 \mu \mathrm{g} / \mathrm{ml}$ & $10 \mu \mathrm{g} / \mathrm{ml}$ & $100 \mu \mathrm{g} / \mathrm{ml}$ & $10 \mu \mathrm{g} / \mathrm{ml}$ & $100 \mu \mathrm{g} / \mathrm{ml}$ & $10 \mu \mathrm{g} / \mathrm{ml}$ & $100 \mu \mathrm{g} / \mathrm{ml}$ \\
\hline \multicolumn{11}{|c|}{ Birch pollen allergics } \\
\hline $\mathrm{HP}$ & 6.5 & 9.5 & 10 & 20 & 0 & 0 & 0 & 0 & 0 & 2 \\
\hline $\mathrm{PH}$ & 8 & 8.5 & 7 & 9.5 & 0 & 0 & 0 & 0 & 0 & 0 \\
\hline SO & 5.5 & 5.5 & 5 & 8 & 0 & 0 & 0 & 0 & ND & ND \\
\hline $\mathrm{SS}_{1}$ & 5.5 & 8 & 6.5 & 9 & 0 & 0 & 0 & 0 & ND & ND \\
\hline $\mathrm{SS}_{2}$ & 6 & 7 & 7 & 16 & 0 & 2 & 0 & 0 & 0 & 0 \\
\hline $\mathrm{SF}_{1}$ & 8 & 8.5 & 8 & 23 & 0 & 0 & 0 & 0 & ND & ND \\
\hline $\mathrm{SF}_{2}$ & 7.5 & 15 & 12.5 & 20 & 0 & 0 & 0 & 0 & 0 & 2 \\
\hline MD & 5.5 & 9.5 & 7 & 12 & 0 & 0 & 0 & 0 & ND & ND \\
\hline \multicolumn{11}{|c|}{ Nonallergic controls } \\
\hline $\mathrm{TB}$ & 6 & 0 & 0 & 0 & 0 & 0 & 0 & 0 & $\mathrm{ND}$ & ND \\
\hline VR & 8.5 & 0 & 0 & 0 & 0 & 0 & 0 & 0 & ND & ND \\
\hline $\mathrm{CD}$ & 6.5 & 0 & 0 & 0 & 0 & 0 & 0 & 0 & ND & ND \\
\hline TL & 9 & 0 & 0 & 0 & 0 & 0 & 0 & 0 & ND & ND \\
\hline
\end{tabular}

Results displayed in the table reflect the mean wheal diameters in $\mathrm{mm}(\mathrm{Dm})$. The initials of the patients are displayed. Two of the birch pollen allergic patients were tested in two independent experiments $\left(\mathrm{SS}_{1}, \mathrm{SS}_{2} ; \mathrm{SF}_{1}, \mathrm{SF}_{2}\right)$. 


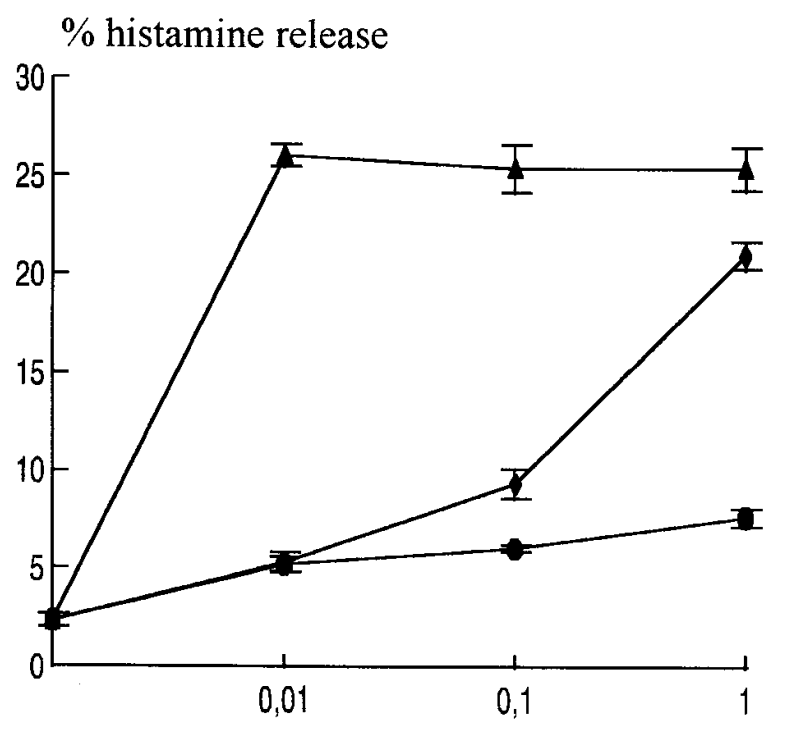

$\mu \mathrm{g} / \mathrm{ml}$

\section{$\%$ histamine release}

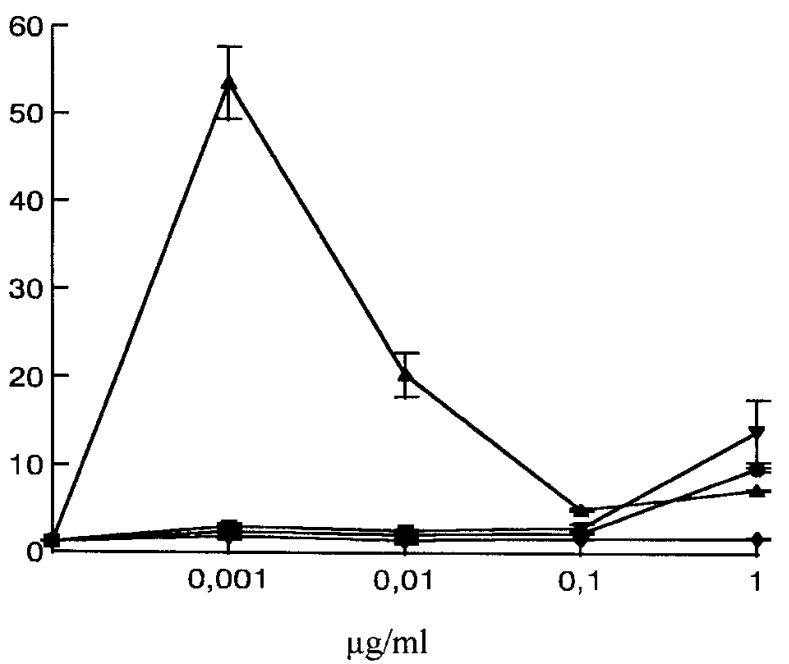

1-160), the two Bet $v 1$ fragments (aa 1-74, aa 75-160), and anti-human IgE antibodies (positive control). Complete recombinant Bet $\mathrm{v} 1$ induced maximal histamine release at a concentration of $0.01 \mu \mathrm{g} / \mathrm{ml}$, whereas a comparable release with the Bet $\mathrm{v} 1$ fragments was not observed up to a concentration of $10 \mu \mathrm{g} / \mathrm{ml}$. An equimolar mixture of both Bet $\mathrm{v} 1$ fragments did not induce significant histamine release compared with each of the fragments tested separately (Fig. 5, bottom) The results from the basophil release experiments correlate with the IgE-binding data, indicating an at least 1,000-fold reduced $\mathrm{IgE}$ binding capacity of the Bet $\mathrm{v} 1$ fragments compared with the complete allergen.

Recombinant Bet $v 1$ fragments do not elicit anaphylactic skin reactions. Table I summarizes the results obtained by skin prick testing of six representative birch pollen allergic patients and four nonallergic individuals with complete recombinant Bet $\mathrm{v} 1$ and recombinant Bet $\mathrm{v} 1$ fragments (aa 1-74, aa
Figure 5. Capacity of recombinant Bet $\mathrm{v} 1$ fragments to induce histamine release. Granulocytes from a birch pollen allergic individual (top) were incubated with different amounts of purified recombinant Bet $\mathrm{v}$ 1 and recombinant Bet $\mathrm{v} 1$ fragments (aa $1-74$, aa $75-160)$ to measure the dose dependency of histamine release. (Bottom) Granulocytes from a different birch pollen allergic patient were tested. In addition to recombinant Bet $\mathrm{v} 1$ and the two fragments, an equimolar mixture of both fragments was used. Histamine released in the cell-free supernatant was measured by RIA (Immunotech) and is expressed as a percentage of total histamine release. Results represent means of triplicate determinations and deviations are indicated for each measurement.
75-160). Individuals were pricked with $20 \mu \mathrm{l}$ of the skin prick solution containing commercial birch pollen extract and using increasing concentrations of purified recombinant Bet $\mathrm{v} 1$ or the Bet v 1 fragments $(10 \mu \mathrm{g} / \mathrm{ml}, 100 \mu \mathrm{g} / \mathrm{ml})$. Complete recombinant Bet $\mathrm{v} 1$ elicited comparable wheal reactions to the natural birch pollen extract and histamine at a concentration of 10 $\mu \mathrm{g} / \mathrm{ml}$. The wheal reaction increased dose dependently with the Bet $\mathrm{v} 1$ concentration. The two Bet $\mathrm{v} 1$ fragments did not induce any wheal reaction up to concentrations of $100 \mu \mathrm{g} / \mathrm{ml}$ in any of the allergic patients or controls. Histamine induced wheal reactions in all four nonallergic control individuals, whereas neither birch extract nor any of the Bet $\mathrm{v} 1$ preparations gave a wheal reaction in the nonallergic group, indicating that the protein preparations were not toxic. $\mathrm{NaCl}$ controls were negative in all individuals tested. To investigate the skin prick activity of an equimolar mixture of both Bet $\mathrm{v} 1$ fragments two additional patients (Table I, $H P$ and $P H$; Fig. 6) and 

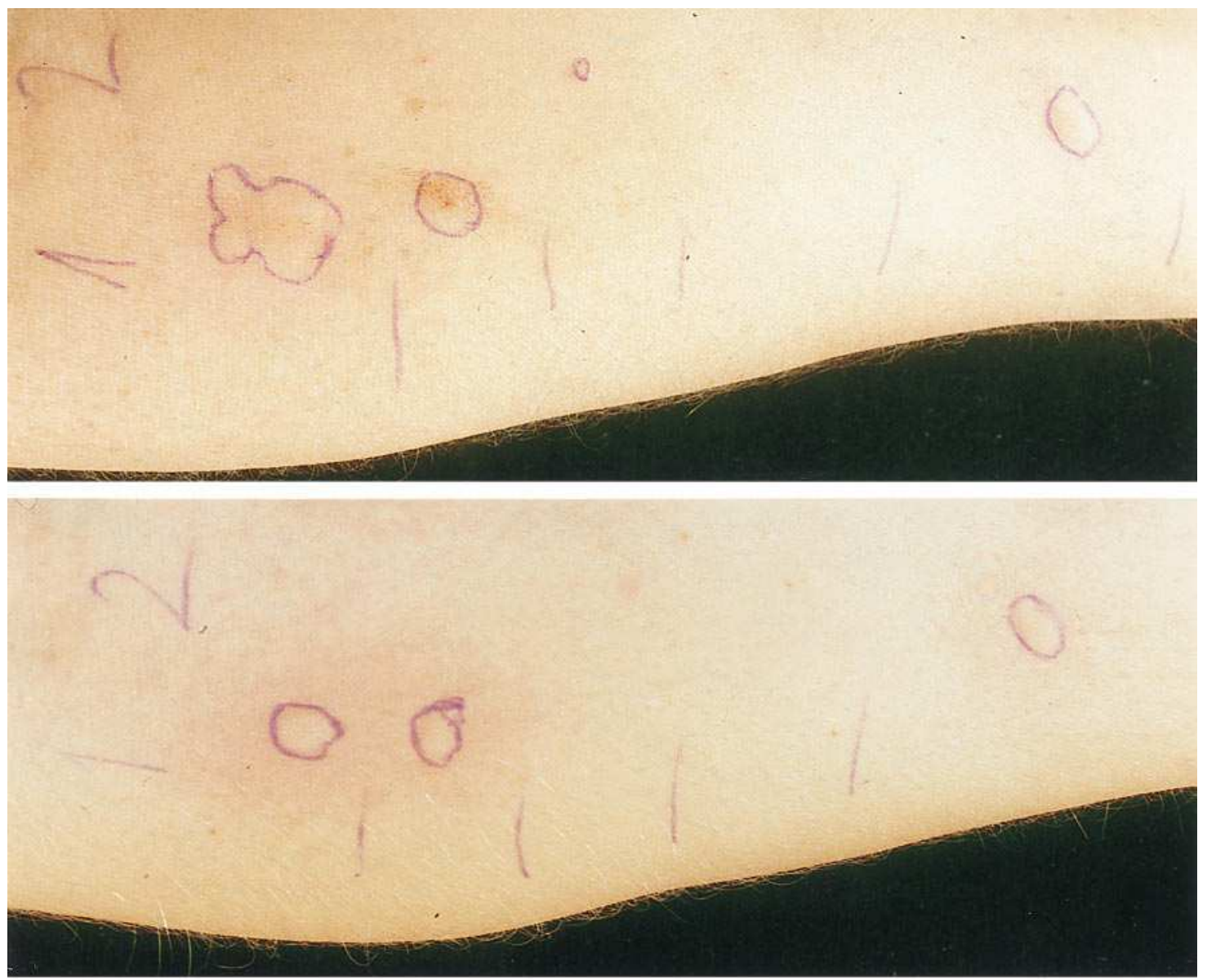

N $\begin{array}{llll}\text { aa } 75-160 & \text { aa } 75-160 & \text { aa } 1-74+ & \text { aa } 1-74+ \\ 100 \mu \mathrm{g} / \mathrm{ml} & 10 \mu \mathrm{g} / \mathrm{ml} & \text { aa } 75-160 & \text { aa } 75-160 \\ 100 \mu \mathrm{g} / \mathrm{ml} & 10 \mu \mathrm{g} / \mathrm{ml}\end{array}$

$\begin{array}{lllll}\text { rBet v } 1 & \text { rBet v } 1 & \text { aa } 1-74 & \text { aa } 1-74 & \text { birch } \\ 100 \mu \mathrm{g} / \mathrm{ml} & 10 \mu \mathrm{g} / \mathrm{ml} & 100 \mu \mathrm{g} / \mathrm{ml} & 10 \mu \mathrm{g} / \mathrm{ml}\end{array}$

Figure 6. Lack of anaphylactic activity of recombinant Bet $\mathrm{v} 1$ fragments. Two birch pollen allergic individuals (top depicts patient HP and the bottom depicts patient $\mathrm{PH}$, both from Table I) were skin pricked on their forearms with different concentrations of recombinant Bet $\mathrm{v}$ 1, recombinant Bet $v 1$ fragments, an equimolar mixture of both fragments, and birch pollen extract.

two previously tested patients (Table $\mathrm{I}, S S_{2}$ and $S F_{2}$ ) were tested also with 10 and $100 \mu \mathrm{g} / \mathrm{ml}$ of an equimolar mixture of both fragments. In none of the patients was a significant wheal reaction (one-third of the histamine wheal) observed up to 100 $\mu \mathrm{g} / \mathrm{ml}$ of the equimolar mixture of both Bet $\mathrm{v} 1$ fragments, confirming that the fragments are unable to reconstitute anaphylactic activity in vivo.

\section{Discussion}

The use of T cell epitopes for specific immunotherapy of type I allergy has been proposed as a possible alternative to current forms of immunotherapy which are based on natural allergen extracts $(4,5,30)$. Anaphylactic side effects during immunotherapy are expected to be significantly reduced if non- $\operatorname{IgE}$ binding $\mathrm{T}$ cell epitopes were used. As a novel approach for the construction of a $\mathrm{T}$ cell allergy vaccine, we have pursued the concept of disrupting conformational IgE epitopes of a relevant allergen by recombinant techniques. Birch pollen allergen, Bet v $1(9,12)$, was chosen as a model because it represents the major allergen for $>95 \%$ of tree pollen and plant food allergic patients and $>60 \%$ of these patients are sensitized exclusively to Bet $v 1(12,13)$. In addition, Bet $v 1$ binds a high percentage of specific serum IgE antibodies and shares $\mathrm{B}$ 
cell as well as $\mathrm{T}$ cell epitopes with homologous allergens present in tree pollen and plant-derived food $(15,16,31-34)$.

In contrast to other allergens which possess continuous IgE epitopes (35), it has been shown that IgE-binding to Bet v 1 and homologous allergens (e.g., the major hazel pollen allergen, Cor a 1) depends on critical amino acid residues which are spread over the molecules. Therefore, it is conceivable that Bet $\mathrm{v} 1$ assembles discontinuous (i.e., conformational) $\mathrm{IgE}$ epitopes. Isovariants of Bet $\mathrm{v} 1$ were shown to have markedly reduced $\mathrm{IgE}$-binding activity although $\mathrm{T}$ cell reactivity was retained $(36,37)$.

By high level expression of corresponding partial cDNA fragments derived from the most frequently recognized Bet $\mathrm{v} 1$ isoform (9), two recombinant Bet $\mathrm{v} 1$ fragments were generated in E. coli. Bet $\mathrm{v} 1$ was divided in two portions representing aa 1-74 and aa 75-160 to maintain the binding site of monoclonal antibodies which were able to modulate IgE-binding to Bet v 1 (21) as well as to preserve the major T cell epitopes (6). The recombinant fragments were expressed separately in $E$. coli and purified to homogeneity. Both recombinant Bet $\mathrm{v} 1$ fragments had almost completely lost their IgE-binding capacity and anaphylactic potential as evaluated by histamine release experiments and by skin prick testing of allergic individuals. All nine tested Bet $v$ 1-specific human $\mathrm{T}$ cell clones showed strong proliferation with at least one of the two recombinant Bet $\mathrm{v} 1$ fragments, indicating that all relevant $\mathrm{T}$ cell epitopes were represented by the two derivatives.

Comparison of the CD spectra of the whole recombinant Bet v 1 (aa 1-160) with the two recombinant Bet v 1 fragments (aa 1-74, aa 75-160) indicated that lack of IgE-binding capacity by the fragments parallels loss of nativelike structure. The CD spectra of the two fragments show features characteristic of a random coil structure which remains unchanged even after prolonged coincubation of equimolar mixtures of the fragments. This result agrees with what is expected on the basis of the secondary structure as determined by nuclear magnetic resonance (38). The fold of Bet $\mathrm{v} 1$ is mainly stabilized by two antiparallel $\beta$ sheets and three helices. Cutting Bet v 1 into two halves would undoubtedly disrupt contacts between secondary structure elements and strongly compromise the protein stability. This is consistent with the finding that neither fragment as single component or as equimolar mixture significantly bound $\mathrm{IgE}$ antibodies or displayed anaphylactic effects in vitro or in vivo. Hence, it is not likely that the fragments would reconstitute the Bet $\mathrm{v} 1$ conformation after injection and cause anaphylactic effects.

Because of the lack of their anaphylactic activity due to disrupture of their tertiary fold, the two Bet v 1 fragments may be considered as safe tools for specific immunotherapy of tree pollen and associated allergies. Vaccination with nonanaphylactic allergen derivatives or peptides which target allergenspecific $\mathrm{T}$ helper cells might lead to disease improvement by (a) induction of tolerance in allergen-specific T cells (39-41); (b) induction of anergy $(42,43)$; (c) perhaps even the switching of allergen-specific TH2 clones into TH1-like clones which may then display a reduced and/or altered cytokine expression (44); or $(d)$ induction of blocking antibodies which are able to recognize the unfolded fragments as well as natural Bet v 1 as exemplified by the mouse monoclonal antibody 14 (21). Although induction of $\mathrm{T}$ cell tolerance against a specific antigen has been demonstrated by injecting a single $\mathrm{T}$ cell epitope derived thereof $(45,46)$, the present approach comprises all known relevant Bet $\mathrm{v} 1 \mathrm{~T}$ cell epitopes. Therefore, allergen fragments without or with markedly reduced allergenicity appear as possible candidates for the treatment of allergic patients by injecting high doses with reduced risk of anaphylactic side effects.

\section{Acknowledgments}

We would like to thank Dr. Markus Susani, Institute of Molecular Biology, Salzburg, Austria for scientific advice concerning protein purification. All experiments carried out on humans were approved by the ethical committee of the University of Vienna and the Austrian Ministry of Health.

This study was supported by grants S06703 and S06704 of the Austrian Science Foundation and a research grant of Pharmacia Diagnostics, Uppsala, Sweden.

\section{References}

1. Kaplan, A.P., editor. 1985. Allergy. Churchill Livingstone, New York.

2. Romagnani, S. 1992. Induction of TH1 and TH2 responses: a key role for the "natural" immune response? Immunol. Today. 13:379-381.

3. Noon, L. 1911. Prophylactic inoculation for hay-fever. Lancet. 1:15721573.

4. Briner, T.J., M.C. Kuo, K.M. Keating, B.L. Rogers, and J.L. Greenstein. 1993. Peripheral T-cell tolerance induced in naive and primed mice by subcutaneous injection of peptides from the major cat allergen Fel d 1. Proc. Natl. Acad. Sci. USA. 90:7608-7612.

5. Norman, P.S. 1993. Modern concepts of immunotherapy. Curr. Opin. Immunol. 5:968-973.

6. Ebner, C., F. Ferreira, Z. Szephalusi, A. Jilek, R. Valenta, P. Parronchi, E. Maggi, S. Romagnani, O. Scheiner, and D. Kraft. 1993. Identification of multiple $\mathrm{T}$ cell epitopes on Bet $\mathrm{v} 1$, the major birch pollen allergen, using specific $\mathrm{T}$ cell clones and overlapping peptides. J. Immunol. 150:1047-1054.

7. Joost-van-Neerven, R., W. van-t'Hof, J.H. Ringrose, H.M. Jansen, R.C. Aalberse, E.A. Wierenga, and M.L. Kapsenberg. 1993. T cell epitopes of house dust mite allergen Der p 2. J. Immunol. 151:2326-2335.

8. Schenk, S., H. Breiteneder, M. Susani, N. Najafian, S. Laffer, M. Duchêne, R. Valenta, G. Fischer, O. Scheiner, D. Kraft, and C. Ebner. 1995. T-cell epitopes of $\mathrm{Phl} \mathrm{p} \mathrm{1,} \mathrm{major} \mathrm{pollen} \mathrm{allergen} \mathrm{of} \mathrm{timothy} \mathrm{grass} \mathrm{(Phleum} \mathrm{pratense):}$ evidence for crossreacting and non-crossreacting T-cell epitopes within grass group I allergens. J. Allergy Clin. Immunol. 96:986-996.

9. Breiteneder, H., K. Pettenburger, A. Bito, R. Valenta, D. Kraft, H. Rumpold, O. Scheiner, and M. Breitenbach. 1989. The gene coding for the major birch pollen allergen Bet $\mathrm{v} 1$, is highly homologous to a pea disease resistance response gene. EMBO (Eur. Mol. Biol. Organ.) J. 8:1935-1938.

10. Visco, V., C. Dolecek, S. Denepoux, J. Le Mao, C. Guret, F. Rousset, M.T. Guinnepain, D. Kraft, R. Valenta, A. Weyer, J. Banchereau, and S. Lebecque. 1996. Human monoclonal antibodies that modulate the binding of specific IgE to birch pollen Bet v 1. J. Immunol. 157:956-962.

11. Laffer, S., L. Vangelista, P. Steinberger, D. Kraft, A. Pastore, and R. Valenta. 1996. Molecular characterization of Bip 1, a monoclonal antibody that modulates IgE binding to birch pollen allergen, Bet v 1. J. Immunol. 157:49534962.

12. Jarolim, E., H. Rumpold, A.T. Endler, H. Ebner, M. Breitenbach, O. Scheiner, and D. Kraft. 1989. IgE and IgG antibodies of patients with allergy to birch as tools to define the allergen profile of Betula verrucosa. Allergy. 44:385395 .

13. Valenta, R., M. Duchêne, S. Vrtala, T. Birkner, C. Ebner, R. Hirschwehr, M. Breitenbach, H. Rumpold, O. Scheiner, and D. Kraft. 1991. Recombinant allergens for immunoblot diagnosis of tree pollen allergy. J. Allergy Clin. Immunol. 88:889-894.

14. Ferreira, F., K. Hoffmann-Sommergruber, H. Breiteneder, K. Pettenburger, C. Ebner, W. Sommergruber, R. Steiner, B. Bohle, W.R. Sperr, P. Valent, et al. 1993. Purification and characterization of recombinant Bet $\mathrm{v} 1$, the major birch pollen allergen. J. Biol. Chem. 268:19574-19580.

15. Ebner, C., R. Hirschwehr, L. Bauer, H. Breiteneder, R. Valenta, H. Ebner, D. Kraft, and O. Scheiner. 1995. Identification of allergens in fruits and vegetables. IgE crossreactivities with the important birch pollen allergens Bet v 1 and Bet v 2 (birch profilin). J. Allergy Clin. Immunol. 95:962-969.

16. Schenk, S., K. Hoffmann-Sommergruber, H. Breiteneder, F. Ferreira, G. Fischer, O. Scheiner, D. Kraft, and C. Ebner. 1994. Four recombinant isoforms of Cor a 1, the major allergen of hazel pollen, show different reactivities with allergen-specific T-lymphocyte clones. Eur. J. Biochem. 224:717-722.

17. Valenta, R., W.R. Sperr, F. Ferreira, P. Valent, C. Sillaber, M. Tejkl, M. Duchêne, C. Ebner, K. Lechner, D. Kraft, and O. Scheiner. 1993. Induction of specific histamine release from basophils with purified natural and recombinant 
birch pollen allergens. J. Allergy Clin. Immunol. 91:88-97.

18. Pauli, G., P. Oster, P. Deviller, S. Heiss, J. Bessot, M. Susani, F. Ferreira, D. Kraft, and R. Valenta. 1996. Skin testing with recombinant allergens rBet v 1 and rBet v 2: diagnostic value for birch pollen and associated allergies. J. Allergy Clin. Immunol. 97:1100-1109.

19. Menz, G., C. Dolecek, U. Schönheit-Kenn, F. Ferreira, M. Moser, T. Schneider, M. Suter, G. Boltz-Nitulescu, C. Ebner, D. Kraft, and R. Valenta. 1996. Serological and skin-test diagnosis of birch pollen allergy with recombinant Bet $v$ I, the major birch pollen allergen. Clin. Exp. Allergy. 26:50-60.

20. Valenta, R., S. Vrtala, C. Ebner, D. Kraft, and O. Scheiner. 1992. Diagnosis of grass pollen allergy with recombinant timothy grass (Phleum pratense) pollen allergens. Int. Arch. Allergy Immunol. 97:287-294.

21. Lebecque, S., C. Dolecek, S. Laffer, V. Visco, S. Denepoux, J.J. Pin, G. Boltz-Nitulescu, A. Weyer, and R. Valenta. 1997. Immunologic characterization of monoclonal antibodies that modulate human $\operatorname{IgE}$ binding to the major birch pollen allergen Bet v 1. J. Allergy Clin. Immunol. In press.

22. Vrtala, S., M. Grote, M. Duchêne, R. van Ree, D. Kraft, O. Scheiner, and R. Valenta. 1993. Properties of tree and grass pollen allergens: reinvestigation of the linkage between solubility and allergenicity. Int. Arch. Allergy Immunol. 102:160-169.

23. Studier, F.W., A.H. Rosenberg, J.J. Dunn, and J.W. Dubendorff. 1990. Use of T7 RNA polymerase to direct expression of cloned genes. Methods Enzymol. 185:60-89.

24. Sanger, F., S. Nicklen, and A.R. Coulson. 1977. DNA sequencing with chain-terminating inhibitors. Proc. Natl. Acad. Sci. USA. 74:5463-5467.

25. Vrtala, S., M. Susani, W.R. Sperr, P. Valent, S. Laffer, C. Dolecek, D. Kraft, and R. Valenta. 1996. Immunologic characterization of purified recombinant timothy grass pollen (Phleum pratense) allergens (Phl p 1, Phl p 2, Phl p 5). J. Allergy Clin. Immunol. 97:781-787.

26. Fling, S.P., and D.S. Gregerson. 1986. Peptide and protein molecular weight determination by electrophoresis using a high-molarity Tris buffer system without urea. Anal. Biochem. 155:83-88.

27. Towbin, H., T. Staehelin, and J. Gordon. 1979. Electrophoretic transfers of proteins from polyacrylamide gels to nitrocellulose sheets: procedure and some applications. Proc. Natl. Acad. Sci. USA. 76:4350-4353.

28. Valenta, R., M. Duchêne, C. Ebner, P. Valent, C. Sillaber, P. Deviller, F. Ferreira, M. Tejkl, H. Edelmann, D. Kraft, and O. Scheiner. 1992. Profilins constitute a novel family of functional plant pan-allergens. J. Exp. Med. 175: 377-385.

29. Valent, P., J. Besmer, M. Muhm, O. Maijdic, K. Lechner, and P. Bettelheim. 1989. Interleukin 3 activates human blood basophils via high-affinity binding sites. Proc. Natl. Acad. Sci. USA. 86:5542-5547.

30. Sheffer, A.L. 1993. Allergen-specific immunotherapy: a role for T-cell anergy. Ann. Allergy. 71:327-329.

31. Rohac, M., T. Birkner, I. Reimitzer, B. Bohle, R. Steiner, M. Breitenbach, D. Kraft, O. Scheiner, F. Gabl, and H. Rumpold. 1991. The immunological relationship of epitopes on major tree pollen allergens. Mol. Immunol. 28 : 897-906.

32. Breiteneder, H., F. Ferreira, A. Reikerstorfer, M. Duchêne, R. Valenta, K. Hoffmann-Sommergruber, C. Ebner, M. Breitenbach, D. Kraft, and O. Scheiner. 1992. Complementary cDNA cloning and expression in Escherichia coli of Aln g 1, the major allergen in pollen of alder (Alnus glutinosa). J. Allergy Clin. Immunol. 90:909-917.

33. Breiteneder, H., F. Ferreira, K. Hoffmann-Sommergruber, C. Ebner, M. Breitenbach, H. Rumpold, D. Kraft, and O. Scheiner. 1993. Four recombinant isoforms of Cor a 1, the major allergen of hazel pollen, show different $\operatorname{IgE}$ binding properties. Eur. J. Biochem. 212:355-362.

34. Hirschwehr, R., R. Valenta, C. Ebner, F. Ferreira, W.R. Sperr, P. Valent, M. Rohac, H. Rumpold, O. Scheiner, and D. Kraft. 1992. Identification of common allergenic structures in hazel pollen and hazelnuts: a possible explanation for sensitivity to hazelnuts in patients allergic to tree pollen. J. Allergy Clin. Immunol. 90:927-936.

35. Ball, T., S. Vrtala, W.R. Sperr, P. Valent, M. Susani, D. Kraft, and R. Valenta. 1994. Isolation of an immunodominant IgE-hapten from an epitope expression cDNA library; dissection of the allergic effector reaction. J. Biol. Chem. 269:28323-28328.

36. Swoboda, I., A. Jilek, F. Ferreira, E. Engel, K. Hoffmann-Sommergruber, O. Scheiner, D. Kraft, H. Breiteneder, E. Pittenauer, E. Schmid, et al. 1995 Isoforms of Bet $\mathrm{v} 1$, the major birch pollen allergen, analyzed by liquid chromatography, mass spectrometry, and cDNA cloning. J. Biol. Chem. 270:2607-2613.

37. Ferreira, F., K. Hirtenlehner, A. Jilek, J. Godnik-Cvar, H. Breiteneder, R. Grimm, K. Hoffmann-Sommeroruber, O. Scheiner, D. Kraft, M. Breitenbach, et al. 1996. Dissection of immunoglobulin $\mathrm{E}$ and $\mathrm{T}$ lymphocyte reactivity of isoforms of the major birch pollen allergen Bet v 1. Potential use of hypoallergenic isoforms for immunotherapy. J. Exp. Med. 183:599-609.

38. Faber, C., A. Lindemann, H. Sticht, A. Ejchart, A. Kungl, M. Susani, R.W. Frank, D. Kraft, M. Breitenbach, and P. Rösch. 1996. The secondary structure and tertiary fold of the birch pollen allergen Bet $\mathrm{v} 1$ in solution. $J$. Biol. Chem. 271:19243-19250.

39. Nossal, G.J. 1993. Tolerance and ways to break it. Ann. NY Acad. Sci. 690:34-41.

40. Boussiotis, V.A., J.G. Gribben, G.J. Freeman, and L.M. Nadler. 1994 Blockade of the CD28 co-stimulatory pathway: a means to induce tolerance. Curr. Opin. Immunol. 6:797-807.

41. Miller, J.F., and R.A. Flavell. 1994. T-cell tolerance and autoimmunity in transgenic models of central and peripheral tolerance. Curr. Opin. Immunol. 6:892-899.

42. Yssel, H., S. Fasler, J. Lamb, and J.E. de Vries. 1994. Induction of nonresponsiveness in human allergen-specific type $2 \mathrm{~T}$ helper cells. Curr. Opin. Immunol. 6:847-852.

43. Müller, D.L., and M.K. Jenkins. 1995. Molecular mechanisms underlying functional T-cell unresponsiveness. Curr. Opin. Immunol. 7:375-381.

44. Secrist, H., C.J. Chelen, Y. Wen, J.D. Marshall, and D.T. Umetsu. 1993. Allergen immunotherapy decreases interleukin 4 production in $\mathrm{CD}^{+}{ }^{+} \mathrm{T}$ cells from allergic individuals. J. Exp. Med. 178:2123-2130.

45. Ria, F., B.M. Chan, M.T. Scherer, J.A. Smith, and M.L. Gefter. 1990. Immunological activity of covalently linked T-cell epitopes. Nature (Lond.). 343:381-383.

46. Aichele, P., D. Kyburz, P.S. Ohashi, B. Odermatt, R.M. Zinkernagel, H Hengartner, and H. Pircher. 1994. Peptide-induced T-cell tolerance to preven autoimmune diabetes in a transgenic mouse model. Proc. Natl. Acad. Sci. USA 91:444-448. 